\title{
Left Unchecked: Political Hegemony in Political Science and the Flaws It Can Cause
}

\author{
L.J Zigerell, Illinois State University
}

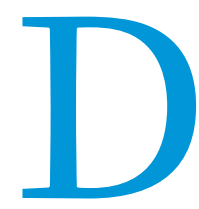

emocrat-to-Republican ratios among political scientists have been estimated at 5.6:1 for reported voting records (Klein and Stern 2005, 264) and at 10:1 for party affiliation (Gross and Simmons 2014, 30). This imbalance might produce negative consequences for political science, but practices can be adopted to reduce these negative consequences.

Inadequate political balance in a discipline can limit the range of research questions (Maranto, Redding, and Hess 2009,5 ) and embed into methods assumptions of the majority group (Duarte et al. 2015, 4ff). Consider the Nteta, Schaffner, and MacWilliams (2017) post on attitudes about the right of professional athletes to kneel during the national anthem to protest the treatment of African Americans. The post reported that whites' strong opposition to this right associated with more negative stereotyping of African Americans relative to whites, controlling for factors such as participant patriotism. However, the post did not report that the data also indicated that strong opposition to this right associated with higher levels of participant patriotism ( $\mathrm{p}<0.001)$ (personal communication with Brian Schaffner). This omission produced a less-balanced understanding than if the post had reported results for participant patriotism.

Or consider research on gender attitudes and support for Donald Trump in Bracic, Israel-Trummel, and Shortle (2018); Cassese and Barnes (2018); Cassese and Holman (2019); Frasure-Yokley (2018); Knuckey (2018); Schaffner, MacWilliams, and Nteta (2018); Setzler and Yanus (2018); and Valentino, Wayne, and Oceno (2018). Each article had "sexism" in the title or abstract, but the gender-attitudes items did not measure attitudes disfavoring men. For example, "to capture gender attitudes," Bracic, Israel-Trummel, and Shortle $(2018,9)$ measured responses only to statements that "Most men are better suited emotionally for politics than are most women" and "A man should be in control of his wife"; these items permitted responses ranging from disfavoring women ("agree" responses) to not disfavoring women ("disagree" responses) but did not permit responses disfavoring men, which could have been captured by, for instance, measuring perceptions of whether-compared to men-women are better, worse, or equally suited for politics (Taylor et al. 2008, 14).

A similar asymmetry occurred in the questionnaires for the 2016 American National Election Studies Time Series
Study (ANES 2017), which by my count in the supplementary materials contained 10 gender-attitudes items about only women and one gender-attitudes item about only men. This item about only men paralleled an item about only women: "How much discrimination is there in the United States today against each of the following groups?" Results for these items are reported in figure 1. If "working from the perspective that denial of discrimination is a manifestation of modern sexism" (Cassese and Barnes 2018, 14), then this denial-of-discrimination manifestation of modern sexism appeared among Donald Trump voters more frequently directed at men than at women and appeared more frequently among Hillary Clinton voters directed at men than among Trump voters directed at women. About half of Clinton voters denied that there is discrimination among men in the United States today, suggesting that many of these voters harbored anti-men attitudes.

Even if these imbalances in gender-attitudes items were due to the reasonable perception that bias against women is or has been larger in politics or in society than bias against men, the dearth of gender-attitudes items about men nonetheless undercuts our understanding about gender attitudes and the 2016 US presidential election, because, even though the previously mentioned articles provided evidence that Trump supporters, on average, reported less positive or sympathetic responses about women than Clinton supporters did, without parallel measures of attitudes about men, the articles cannot support inferences about whether Clinton was on net disadvantaged because of gender attitudes among the electorate.

Researchers interested in how patriotism associates with anthem-protest attitudes or how attitudes about men associate with 2016 US presidential-candidate preference could produce publications that parallel these articles. However, such balancing is implausible as an effective mechanism for countering politically asymmetric research, given the political imbalance in political science membership. Nonetheless, more balanced research might be produced through a stronger peer-review process, which, in the previous examples, suggested or required (1) reporting of results for participant patriotism, or (2) a battery on the 2016 ANES that measured attitudes about men.

Inadequate political balance in an academic discipline might undercut the vetting of research findings (Lukianoff and 
Haidt 2018, 109; Tetlock 1994, 510). The political imbalance in political science produces a nontrivial chance that no peers on the political right would be invited to review a manuscript with an implication favoring the political left, which plausibly reduces the rigor of the peer-review process, given evidence that "liberals were better at identifying flawed arguments supporting conservative beliefs and conservatives were better at identifying flawed arguments supporting liberal beliefs" than to correct published articles, there does not appear to be a mechanism to require comments in these systems to be addressed. Nonetheless, journals could post online conditionally accepted manuscripts, permit public comments on these manuscripts similar to public comments for the ANES Online Commons, and then require that a manuscript address particular conditional-acceptance comments as a condition of publication (see Meta-Psychology for a peer-review process

\section{Researchers interested in how patriotism associates with anthem-protest attitudes or how attitudes about men associate with 2016 US presidential-candidate preference could produce publications that parallel these articles. However, such balancing is implausible as an effective mechanism for countering politically asymmetric research, given the political imbalance in political science membership.}

(Gampa et al. 2019, 29) and meta-analysis evidence that "both liberals and conservatives show a consistent tendency to be less skeptical consumers of information that supports rather than challenges their political beliefs" (Ditto et al. 2019). A plausible method to strengthen peer review is for journals to open manuscript review to volunteers, thereby increasing the number of reviews from skeptics of a manuscript's inferences.

Commenting systems such as Hypothesis and PubPeer are available, respectively, for Open Science Framework preprints (Staines 2018) and post-publication review; however, other

Figure 1

\section{Ratings of No Discrimination against Women and Men}

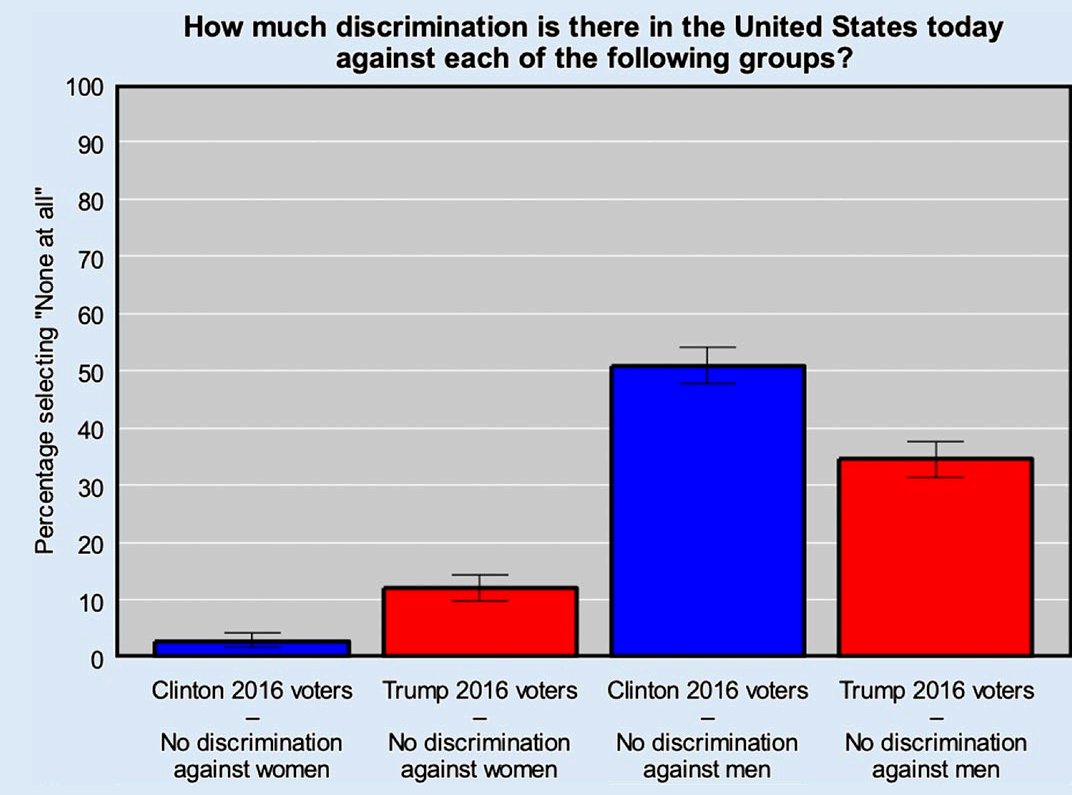

Note: The figure reports weighted percentages and 95\% confidence intervals for Hillary Clinton voters and Donald Trump voters who selected "None at all" for targets of women or men when asked: "How much discrimination is there in the United States today against each of the following groups?"; other response options were "A great deal," "A lot," "A moderate amount," and "A little." Analyses were conducted in Stata 15 (StataCorp 2017). The figure was produced in R (R Core Team 2018) with ggplot2 (Wickham 2016). Data: American National Election Studies, University of Michigan, and Stanford University (2017). that incorporates public comments, available at https://web. archive.org/web/20180315124052/https://open.lnu.se/index. hp/metapsychology/about).

Conditional-acceptance comments would not be needed reject-or-accept recommendations but instead could idenpotential manuscript flaws that nonpublic peer review have missed. Consider Mitchell and Martin (2018,648) uations and Rate My Professors comments for one woman instructor to corresponding evaluations and comments for one man instructor, in which "Findings suggest that the relationship between gender and teaching evaluations may indicate that the use of evaluations in employment decisions is discriminatory against women." Conditionalacceptance comments about Mitchell and Martin (2018) could have (1) noted that, in table 2 , the use of one asterisk to indicate a p-value under 0.1 for an $\mathrm{N}=54$ difference between $0 \%$ and $6.6 \%$ is apparently inconsistent with the use of two asterisks to indicate a p-value under 0.05 for an $\mathrm{N}=54$ difference between $\mathrm{o} \%$ and $5.5 \%$; (2) requested that the manuscript indicate whether the table $1 \mathrm{~N}=68$ for the official university course evaluations and the table $2 \mathrm{~N}=54$ for the Rate My Professors comments are perinstructor sample sizes (in the unlikely event that the two instructors had identical numbers of comments in each table) or are pooled-across-instructor sample sizes and, if the latter, requested the instructor-level Ns that could have produced the $\mathrm{p}$-values indicated by the asterisks; and (3) inquired whether table 4 inferential statistics were from analyses that treated multiple ratings 
from a student in a category as independent ratings, as suggested by reported sample sizes (see the supplementary materials). A Mitchell and Martin (2018) addressing these comments might be less likely to be accepted as evidence that "student course evaluations...have been shown to be biased against female instructors" (Sen 2018, 336).

In addition to opening peer review to volunteers, journal editors can reduce the potential for political imbalance in research reporting by adopting policies to further reduce reporting flexibility, given that reported estimates and inferences can depend on how data are analyzed and on whether data are omitted from reported analyses (Simmons, Nelson, and Simonsohn 2011; Zigerell 2017). Journal policies to further reduce reporting flexibility can, for instance, require that articles reporting on nonpublic surveys include full questionnaires in the article or appendices, with reasonable exceptions.

Political imbalance in political science also might bias which perceived problems are addressed in the discipline. For example, in 2018, the American Political Science Association (APSA) had status committees on Asian Pacific Americans; blacks; community colleges; contingent faculty; first-generation scholars; graduate students; Latinos and Latinas; women; and lesbians, gays, bisexuals, and transgender individuals (APSA 2018c). The charge for APSA's Committee on the Status of Women in the Profession discussed discrimination and underrepresentation of women (APSA 2018a), and these concerns also could also explain establishment of other status committees. However, APSA has no status committee on political minorities, despite evidence that some academics are willing to discriminate based on ideology (Honeycutt and Freberg 2017) and despite the previously mentioned evidence of Republican underrepresentation in political science relative to the US population.
"Statement on Professional Ethics" endorsed in APSA's "A Guide to Professional Ethics in Political Science," that professors "avoid any exploitation, harassment, or discriminatory treatment of students" and "do not discriminate against or harass colleagues" (APSA 2012, 5; emphasis added), the APSA Committee on Professional Ethics, Rights, and Freedoms should issue an advisory opinion regarding ethical limits on protected-class discrimination in the discipline. Given the importance of peer evaluations to professional advancement in political science, the committee also could indicate whether political scientists involved in open protected-class discrimination against students or colleagues should recuse themselves from nonblinded decision making in domains such as hiring-even if only to avoid risking the appearance of bias in such decisions.

Moreover, APSA can provide nondiscriminatory alternatives. For example, as an alternative to the exclusionary lists of experts maintained by Women Also Know Stuff and People of Color Also Know Stuff, APSA could maintain a list of experts open to everyone in the discipline that permits filtering by expert characteristics such as gender identity, race, and volunteered ideology, which could permit selection of a diverse set of experts and permit more intersectionality in searches than lists that exclude experts because of their gender identity or color.

The optimal policy for political science might not be nondiscrimination but instead be modeled on US equalprotection jurisprudence to help cabin discrimination to discrimination that, for instance, is narrowly tailored to further a compelling discipline interest, such as remediating effects of unfair discrimination in the discipline's past or present, producing a diverse set of experts for an event, or reducing political asymmetry in questionnaires for publicly funded surveys. In these cases, for discrimination justified on empirical claims, discipline discriminators could announce

\section{Political science can be improved if its members and leaders adopt practices that help avoid negative consequences of political asymmetry in its membership and leadership.}

Political imbalance in political science might influence the choice of policies to address perceived problems. General Social Survey data (Smith et al. 2019) indicated that, in 2018 and between 2000 and 2018 inclusive, strong Democrats and extreme liberals were more likely than strong Republicans and extreme conservatives to favor preferential hiring and promotion of women, with and without controls for sex, race, age, and education. Similar preferential treatment occurs in political science, with women explicitly favored in the provision of publicity by the Women Also Know Stuff project and in the provision of educational opportunities at Visions in Methodology conferences and Journeys in World Politics workshops (see the supplementary materials). To the extent that such discrimination is in tension with principles from the American Association of University Professors (2009) the criteria that could be met to stop or reverse their discrimination. For example, APSA webpages list Asian Pacific Americans as one of the "underrepresented racial or ethnic minority groups" for which Ralph Bunche Summer Institute Program eligibility criteria are relaxed (APSA 2019) and as possessing one of the "underrepresented backgrounds" permitting eligibility for the Minority Student Recruitment Program (APSA 2018b). However, it is unclear how underrepresentation is determined, given that Mealy $(2018,2)$ reported that, in US-based APSA data, "East Asian or Asian American membership is slightly higher in percentage than the US Asian American population."

Political science can be improved if its members and leaders adopt practices that help avoid negative consequences of political asymmetry in its membership and leadership. It is hoped 
that this includes the practices listed here and other practices that can be agreed upon by political scientists of good faith.

\section{SUPPLEMENTARY MATERIAL}

To view supplementary material for this article, please visit https://doi.org/10.1017/S1049096519000854

\section{ACKNOWLEDGMENTS}

I thank Lonna Atkeson, James E. Campbell, Mark Carl Rom, an anonymous reviewer, and others for comments, and Brian Schaffner for information and permission to cite results.

\section{REFEREN CES}

American Association of University Professors. 2009. "Statement on Professional Ethics." Adopted 1966, revised 1987 and 2009. Available at https://web.archive. org/web/20181116010502/https:/www.aaup.org/report/statement-professionalethics.

American National Election Studies (ANES). 2017. "User's Guide and Codebook for the ANES 2016 Time Series Study." Ann Arbor, MI, and Palo Alto, CA: University of Michigan and Stanford University.

American National Election Studies, University of Michigan and Stanford University. 2017. "ANES 2016 Time Series Study." Ann Arbor, MI: Inter-University Consortium for Political and Social Research [distributor], 2017-09-19. Available at https://doi.org/10.3886/ICPSR36824.v2.

American Political Science Association. 2012. "A Guide to Professional Ethics in Political Science." Second edition. Washington, DC.

American Political Science Association. 2018a. "Committee on the Status of Women in the Profession." Available at https://web.archive.org/ web/20180329122250/http://www.apsanet.org/statuscommitteewomen.

American Political Science Association. 2018b. "Minority Student Recruitment Program." Available at https:/web.archive.org/web/20180429130116/http:// www.apsanet.org/msrp.

American Political Science Association. 2018c. "Status Committees." Available at https://web.archive.org/web/20180429130141/https://www.apsanet.org/ status-committees.

American Political Science Association. 2019. "Ralph Bunche Summer Institute Application Process." Available at https://web.archive. org/web/20190201140935/https:/www.apsanet.org/DIVERSITY/ Ralph-Bunche-Summer-Institute/How-to-Apply.

Bracic, Ana, Mackenzie Israel-Trummel, and Allyson F. Shortle. 2018. "Is Sexism for White People? Gender Stereotypes, Race, and the 2016 Presidential Election." Political Behavior (Early View): 1-27.

Cassese, Erin C., and Tiffany D. Barnes. 2018. "Reconciling Sexism and Women's Support for Republican Candidates: A Look at Gender, Class, and Whiteness in the 2012 and 2016 Presidential Races." Political Behavior (Early View): 1-24.

Cassese, Erin C., and Mirya R. Holman. 2019. "Playing the Woman Card: Ambivalent Sexism in the 2016 US Presidential Race.” Political Psychology 40 (1): 55-74.

Ditto, Peter H., Brittany S. Liu, Cory J. Clark, Sean P. Wojcik, Eric E. Chen, Rebecca H. Grady, Jared B. Celniker, and Joanne F. Zinger. 2019. "At Least Bias Is Bipartisan: A Meta-Analytic Comparison of Partisan Bias in Liberals and Conservatives." Perspectives on Psychological Science $14(2): 273-91$

Duarte, José L., Jarret T. Crawford, Charlotta Stern, Jonathan Haidt, Lee Jussim, and Philip E. Tetlock. 2015. "Political Diversity Will Improve Social Psychological Science." Behavioral and Brain Sciences 38: e130.

Frasure-Yokley, Lorrie. 2018. "Choosing the Velvet Glove: Women Voters, Ambivalent Sexism, and Vote Choice in 2016." Journal of Race, Ethnicity and Politics 3 (1): 3-25.

Gampa, Anup, Sean Wojcik, Matt Motyl, Brian A. Nosek, and Peter Ditto. 2019. "(Ideo)logical Reasoning: Ideology Impairs Sound Reasoning." PsyArXiv, January 13. Available at doi:10.31234/osf.io/hspjz.

Gross, Neil, and Solon Simmons. 2014. "The Social and Political Views of American College and University Professors." In Professors and Their Politics, ed. Neil Gross and Solon Simmons, 19-50. Baltimore, MD: Johns Hopkins University Press.
Honeycutt, Nathan, and Laura Freberg. 2017. "The Liberal and Conservative Experience across Academic Disciplines: An Extension of Inbar and Lammers." Social Psychological and Personality Science 8 (2): 115-23.

Klein, Daniel B., and Charlotta Stern. 2005. "Professors and Their Politics: The Policy Views of Social Scientists." Critical Review 17 (3-4): 257-303.

Knuckey, Jonathan. 2018. “'I Just Don't Think She Has a Presidential Look' Sexism and Vote Choice in the 2016 Election." Social Science Quarterly (Early View): 1-17.

Lukianoff, Greg, and Jonathan Haidt. 2018. The Coddling of the American Mind: How Good Intentions and Bad Ideas Are Setting up a Generation for Failure. London: Penguin Press.

Maranto, Robert, Richard E. Redding, and Frederick M. Hess. 2009. "The PC Academy Debate: Questions Not Asked." In The Politically Correct University: Problems, Scope, and Reforms, ed. Robert Maranto, Richard E. Redding, and Frederick M. Hess, 3-14. Lanham, MD: Rowman \& Littlefield.

Mealy, Kimberly A. 2018. "Diversity and Inclusion Report." Executive Summary Version. Available at https://web.archive.org/web/20190228141716/https:// www.apsanet.org/Portals/54/diversity\%20and\%2oinclusion\%2oprgms/ DIV\%2oreports/Diversity\%2oReport\%2oExecutive\%20-\%20Final\%20 Draft\%20-\%2oWeb\%2oversion.pdf?ver=2018-03-29-134427-467.

Mitchell, Kristina M. W., and Jonathan Martin. 2018. "Gender Bias in Student Evaluations." PS: Political Science \& Politics 51 (3): 648-52.

Nteta, Tatishe M., Brian Schaffner, and Matthew C. MacWilliams. 2017. "Racially Biased People Are Far More Likely to Oppose Black Athletes' Protests. Here's the Evidence." The Monkey Cage, April 20. Available at https://web.archive.org/web/20170804211349/https://www.washingtonpost. com/news/monkey-cage/wp/2017/o4/20/racial-bias-is-behind-oppositionto-black-athletes-protests-heres-the-evidence/.

R Core Team. 2018. "R: A Language and Environment for Statistical Computing." Vienna, Austria: R Foundation for Statistical Computing. Available at www.R-project.org.

Schaffner, Brian F., Matthew MacWilliams, and Tatishe Nteta. 2018. "Understanding White Polarization in the 2016 Vote for President: The Sobering Role of Racism and Sexism." Political Science Quarterly 133 (1): 9-34.

Sen, Maya. 2018. "Response to Dion, Sumner, and Mitchell." Political Analysis 26 (3): 335-37.

Setzler, Mark, and Alixandra B. Yanus. 2018. "Why Did Women Vote for Donald Trump?" PS: Political Science \& Politics 51 (3): 523-27.

Simmons, Joseph P., Leif D. Nelson, and Uri Simonsohn. 2011. "FalsePositive Psychology: Undisclosed Flexibility in Data Collection and Analysis Allows Presenting Anything as Significant." Psychological Science 22 (11): 1359-66.

Smith, Tom W., Michael Davern, Jeremy Freese, and Michael Hout. 2019. "General Social Surveys, 1972-2018" [machine-readable data file]. Principal Investigator, Tom W. Smith; Co-Principal Investigators, Michael Davern, Jeremy Freese, and Stephen L. Morgan, NORC Editor. Chicago: National Opinion Research Center. One data file $(64,814$ logical records) and one codebook (3,758 pages).

Staines, Heather. 2018. "Hypothesis and the Center for Open Science Collaborate on Annotation." Hypothesis, February 8. Available at https://web.archive.org/web/20181025174806/https://web.hypothes.is/ blog/cos-launch/.

StataCorp. 2017. "Stata Statistical Software: Release 15." College Station, TX: StataCorp LLC.

Taylor, Paul, Rich Morin, D’Vera Cohn, April Clark, and Wendy Wang. 2008. "A Paradox in Public Attitudes-Men or Women: Who's the Better Leader?" Pew Research Center. Available at www.pewresearch.org/wpcontent/uploads/sites/3/2010/10/gender-leadership.pdf.

Tetlock, Philip E. 1994. "Political Psychology or Politicized Psychology: Is the Road to Scientific Hell Paved with Good Moral Intentions?" Political Psychology 15 (3): 509-29.

Valentino, Nicholas A., Carly Wayne, and Marzia Oceno. 2018. "Mobilizing Sexism: The Interaction of Emotion and Gender Attitudes in the 2016 US Presidential Election." Public Opinion Quarterly 82 (S1): 213-35.

Wickham, Hadley. 2016. "ggplot2: Elegant Graphics for Data Analysis." New York: Springer-Verlag.

Zigerell, L. J 2017. "Reducing Political Bias in Political Science Estimates." PS: Political Science \& Politics 50 (1): 179-83. 